SUPPLEMENTARY INFORMATION

\title{
The Side-On versus End-On Binding Modes Between Metal Cations and (NHC)AlAl(NHC)
}

Huaiyu Zhang a,*, Rui Yuan a , Jinshuai Song ${ }^{\mathrm{b}}$, Xiaoyan Li a, Yanli Zeng a,*, Yirong Mo ${ }^{\mathrm{c}, *}$

a. Institute of Computational Quantum Chemistry, College of Chemistry and Material Science, Hebei Normal University, Shijiazhuang, China

b. College of Chemistry, and Institute of Green Catalysis, Zhengzhou University, Zhengzhou, 450001, China

c. Department of Nanoscience, Joint School of Nanoscience and Nanoengineering, University of North Carolina at Greensboro, Greensboro, NC 27401, USA

1. The Cartesian coordinates $\mathrm{C}_{2}-(\mathrm{NHC}) \mathrm{AlAl}(\mathrm{NHC})$ and $\mathrm{C}_{2 \mathrm{~h}}-(\mathrm{NHC}) \mathrm{AlAl}(\mathrm{NHC})$ $\mathrm{C}_{2}$-(NHC)AlAl(NHC)

The Cartesian coordinates see xyz file.

\section{Other possible structures of (NHC)AlAl(NHC)}

(a) A structure where the $\mathrm{NHC}$ and $\mathrm{Al}_{2}$ planes are perpendicular to each other. Its energy is higher than the one in main text by $4.02 \mathrm{kcal} / \mathrm{mol}$.

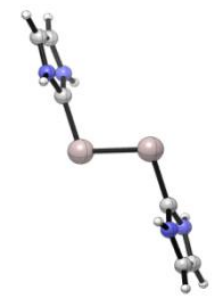

The Cartesian coordinates see xyz file.

(b) The cis-(NHC)AlAl(NHC)

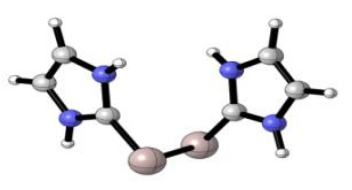

The Cartesian coordinates see xyz file. 


\section{The Cartesian coordinates MP2/6-311+G(d)}

The Cartesian coordinates see xyz file.

\section{The check to spin states and wave function}

The monomer and $\mathrm{Li}^{+}$and end-on $\mathrm{Cu}^{+}$complexes are taken as examples to check the favorable spin state and the reasonability of wave function. Our results show that the triplet state is more stable than singlet state by $7.10 \mathrm{kcal} / \mathrm{mol}$ for monomer, while just the opposite happened in $\mathrm{Li}^{+}$ and $\mathrm{Cu}^{+}$complexes. The energy difference between singlet and triplet state is 9.41 and 28.39 $\mathrm{kcal} / \mathrm{mol}$, respectively. Since our focus in this work is on the bonding between Al-Al core and metal cations, the singlet state is adopted in our work.

In addition, $\operatorname{CASSCF}(4,4)$ calculations were performed. For monomer and $\mathrm{Li}^{+}$complexes, the active space comprised the $\pi$ bond, nonclassical "slipped" $\pi$ bond and the corresponding unoccupied anti- $\pi$. For end-on $\mathrm{Cu}^{+}$complexes, the $\mathrm{Al}-\mathrm{Cu}$ bonds and the corresponding unoccupied orbitals are include in the active space. By examination to orbitals and the coefficients of HF determinant (Table S1), we confirmed the reasonability of DFT wave function.

At last, the wave function stability has also been tested using Gaussian software and the results show that they are stable.

Table S1. The coefficients of HF determinant in CASSCF wavefunction.

\begin{tabular}{cc}
\hline & Coefficients \\
\hline (NHC)AlAl(NHC) & 0.8990 \\
$\mathrm{Li}_{2}[(\mathrm{NHC}) \mathrm{AlAl}(\mathrm{NHC})]^{2+}$ & 0.9342 \\
$\mathrm{Cu}_{2}[(\mathrm{NHC}) \mathrm{AlAl}(\mathrm{NHC})]^{2+}$ & 0.9987 \\
\hline
\end{tabular}

\section{Energetic flowchart for a hypothetical process of formation of (NHC)AIAI(NHC) from the ground states of $\mathrm{Al}_{2}$ and $\mathrm{NHC}$}

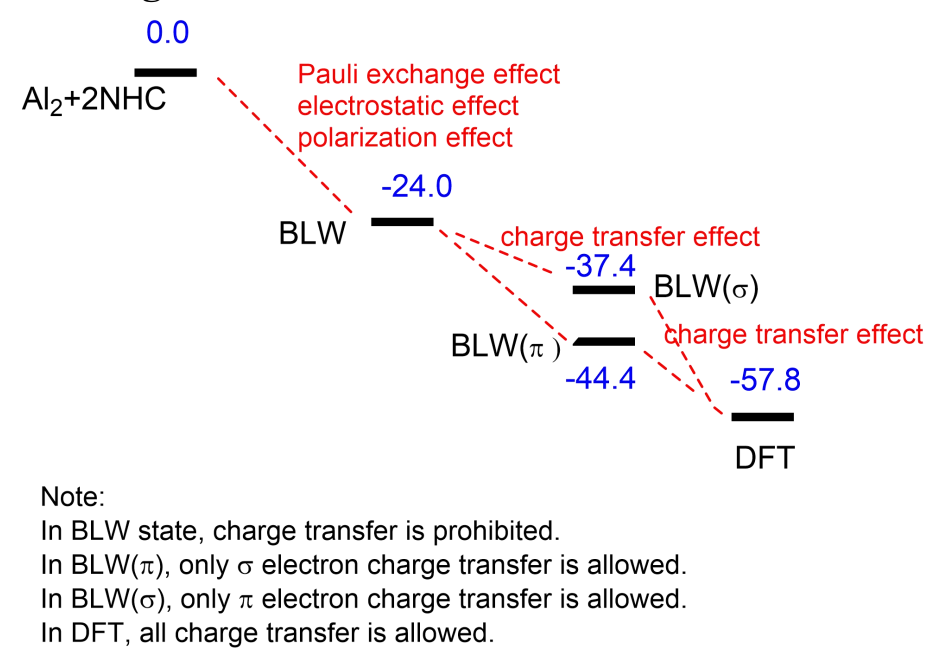




\section{VB method}

Valence bond (VB) theory and molecular orbital (MO) theory are two general theories of bonding in molecular quantum mechanics. In MO theory all MOs are delocalized to the whole system, while in VB theory local and nonorthogonal orbitals are used to construct electron localized resonance states with Heitler-London-Slater-Pauling (HLSP) functions each of which is essentially a combination of a number of Slater determinants andthe final molecular wavefunction $\Psi$ is a superposition of several key resonance states as ${ }^{1-5}$

$$
\Psi=\sum_{K} C_{K} \Phi_{K}
$$

Eq. 1

where $\Phi_{K}$ corresponds to VB structures $\mathbf{I}^{\prime}$ to $\mathbf{I V}^{\prime}$, and $C_{K}$ is the corresponding structural coefficients. The relative weights of VB structures are derived by the Coulson-Chirgwin formula ${ }^{6}$

$$
W_{K}=C_{K}^{2}+\sum_{K \neq L} C_{K} C_{L} S_{K L}
$$

Eq. 2

where $S_{K L}$ is the overlap integral of two VB structures.

There are several computational approaches for VB theory at the ab initio level. In the VB self-consistent field (VBSCF) procedure, both the VB orbitals and structural coefficients are optimized simultaneously to minimize the total energy. ${ }^{7}$ In our work, the VBSCF calculations were carried out with the Xiamen Valence Bond (XMVB) program ${ }^{8,} 9$ with the M06-2x/ 6-311+G(d) geometries and the 6-31G(d) basis set.

\section{The $\left.\mathrm{M}_{2}{ }_{2}[\mathrm{NHC}) \mathrm{AlAl}(\mathrm{NHC})\right]^{2+}$ studied in our work.}

The Cartesian coordinates see xyz file.

\section{Other possible bonding patterns of $\mathbf{M}_{2}^{\prime}[(\mathrm{NHC}) \mathrm{AlAl}(\mathrm{NHC})]^{2+}$}

The Cartesian coordinates see xyz file.

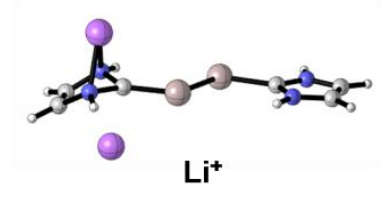

Figure S1. Other bonding patterns of $\mathrm{M}_{2}^{\prime}[(\mathrm{NHC}) \mathrm{AlAl}(\mathrm{NHC})]^{2+}$ such as cation-heterocycle-complexes.

\section{The natural bond orbitals of $\mathrm{M}_{2}^{\prime}[(\mathrm{NHC}) \mathrm{Al} \equiv \mathrm{Al}(\mathrm{NHC})]^{2+}$}



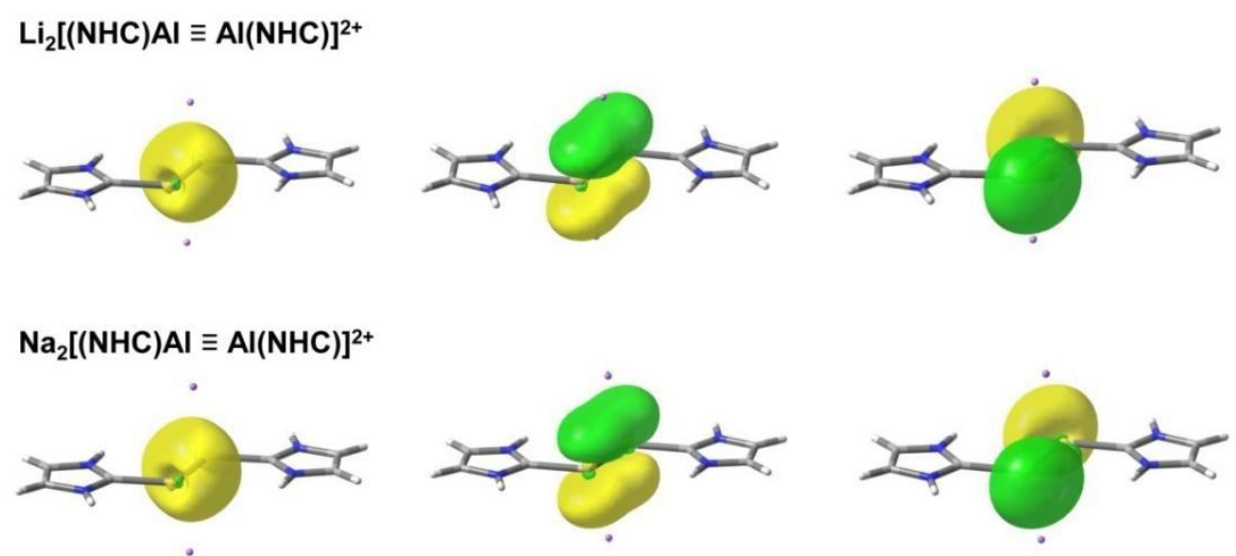

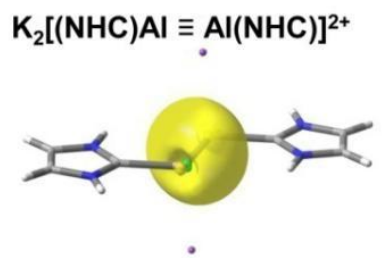

(a)

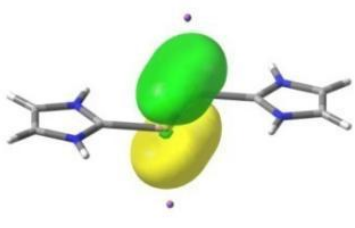

(b)

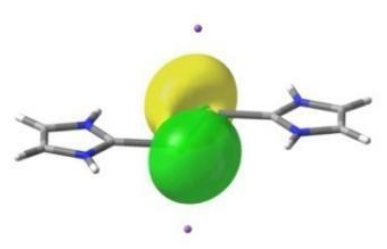

(c)

Figure S2. The natural bond orbitals of $\mathrm{M}_{2}^{\prime}[(\mathrm{NHC}) \mathrm{AlAl}(\mathrm{NHC})]^{2+}\left(\mathrm{M}^{\prime}=\mathrm{Li}, \mathrm{Na}, \mathrm{K}\right)(\mathrm{a}) \mathrm{Al}-\mathrm{Al} \sigma$ bond (b) Al-Al $\pi$ bond (c) Al-Al nonclassical "slipped" $\pi$ bond.

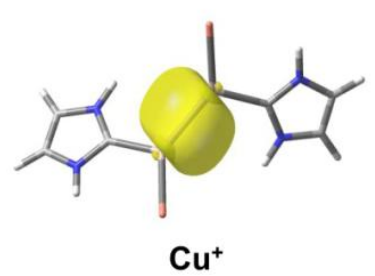

$\mathrm{Cu}^{+}$

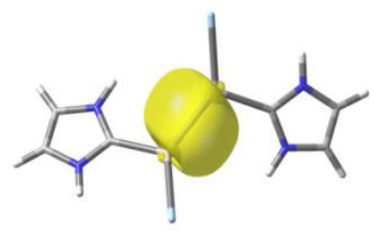

$\mathrm{Ag}^{+}$

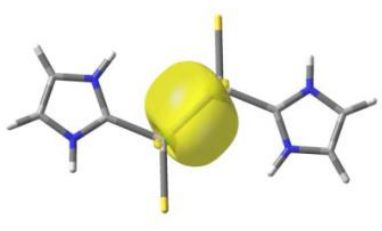

$\mathrm{Au}^{+}$

Figure S3. The Al-Al $\sigma$ bond of $\mathrm{M}_{2}^{\prime}[(\mathrm{NHC}) \mathrm{AlAl}(\mathrm{NHC})]^{2+}\left(\mathrm{M}^{\prime}=\mathrm{Cu}, \mathrm{Ag}, \mathrm{Au}\right)$

9. How point charges (background charge distribution) are included in distorted (the dihedral angle of $\mathrm{C}-\mathrm{Al}-\mathrm{Al}-\mathrm{C}$ are kept 90 degree) and $\mathrm{C}_{2 \mathrm{~h}}$ (NHC)AlAl(NHC)

Two point charges (the charge is 1 ) are attached at $2.5 \AA$ away from $\mathrm{Al}$ atoms. The calculations are carried out by the keyword "Charge" in Gaussian 09. It can help us check the effect of electrostatic interaction.

10. The optimized geometries and natural bond orbitals $\mathrm{M}_{2}^{\prime}[\mathrm{Ph}-\mathrm{Al}-\mathrm{Al}-\mathrm{Ph}]$ and $\mathbf{M}_{2}{ }_{2}[\mathrm{Ph}-\mathrm{Si}-\mathrm{Si}-\mathrm{Ph}]^{2+}$ 
(a) $\mathrm{M}_{2}[\mathrm{Ph}-\mathrm{Al}-\mathrm{Al}-\mathrm{Ph}]$
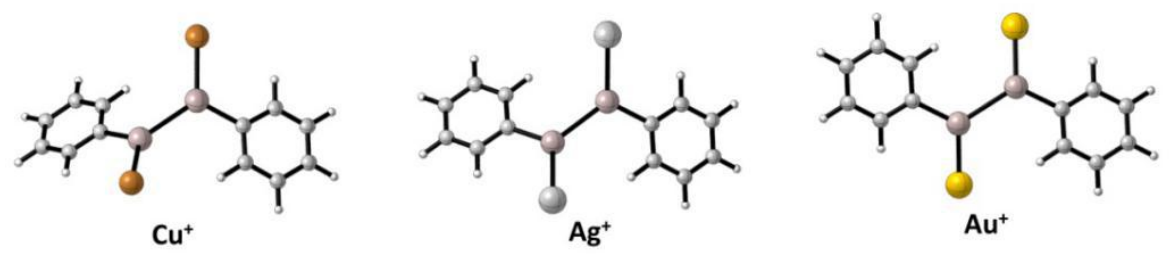

(b) $\mathrm{M}_{2}[\mathrm{Ph}-\mathrm{Si}-\mathrm{Si}-\mathrm{Ph}]^{2+}$
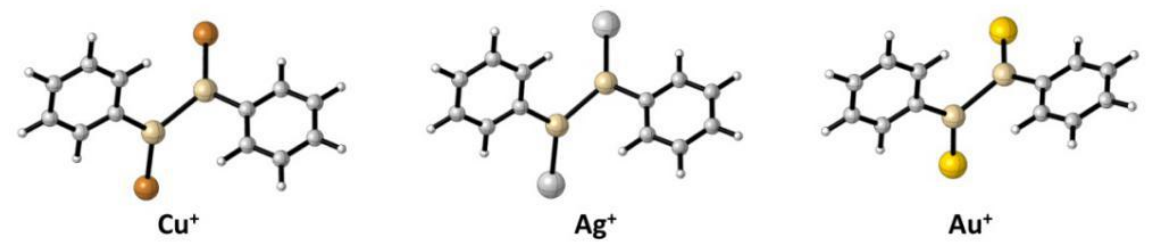

Figure S4. The optimized geometries of $\mathrm{M}_{2}^{\prime}[\mathrm{Ph}-\mathrm{Al}-\mathrm{Al}-\mathrm{Ph}]$ and $\mathrm{M}_{2}^{\prime}[\mathrm{Ph}-\mathrm{Si}-\mathrm{Si}-\mathrm{Ph}]^{2+}$.

The Cartesian coordinates see xyz file.

$\mathrm{Cu}_{2}[\mathrm{Ph}-\mathrm{Al}-\mathrm{Al}-\mathrm{Ph}]$

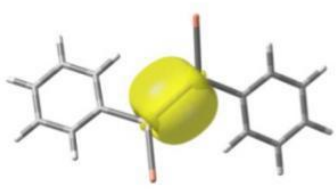

$\mathrm{Ag}_{2}[\mathrm{Ph}-\mathrm{Al}-\mathrm{Al}-\mathrm{Ph}]$

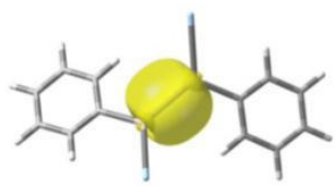

$\mathrm{Au}_{2}[\mathrm{Ph}-\mathrm{Al}-\mathrm{Al}-\mathrm{Ph}]$

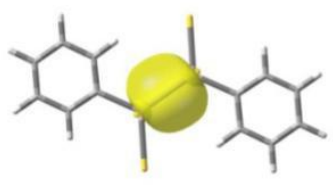

(a)
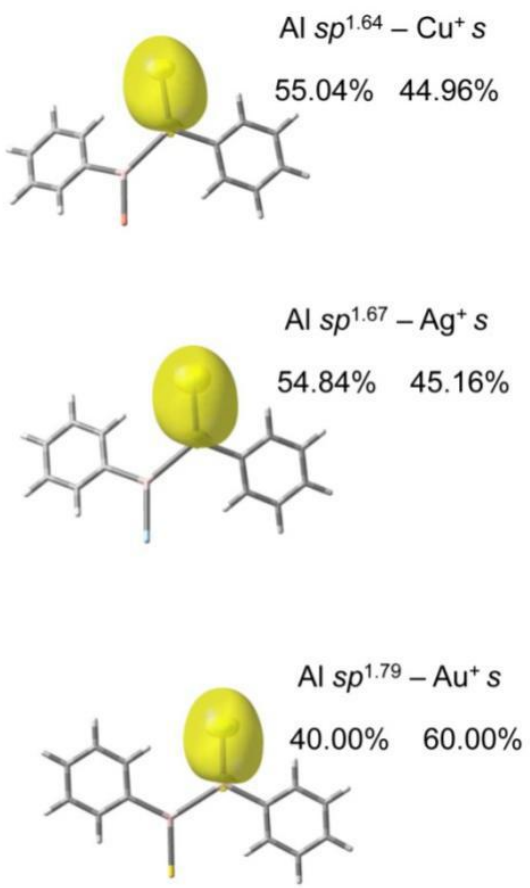

(b)

Figure S5. The natural bond orbitals of $\mathrm{M}_{2}^{\prime}[\mathrm{Ph}-\mathrm{Al}-\mathrm{Al}-\mathrm{Ph}]\left(\mathrm{M}^{\prime}=\mathrm{Cu}, \mathrm{Ag}, \mathrm{Au}\right)(\mathrm{a}) \mathrm{Al}-\mathrm{Al} \sigma$ bond (b) one of Al- M' bonds. 
$\mathrm{Cu}_{2}[\mathrm{Ph}-\mathrm{Si}-\mathrm{Si}-\mathrm{Ph}]^{2+}$

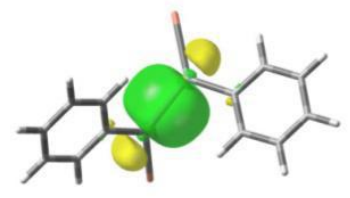

$\mathrm{Ag}_{2}[\mathrm{Ph}-\mathrm{Si}-\mathrm{Si}-\mathrm{Ph}]^{2+}$

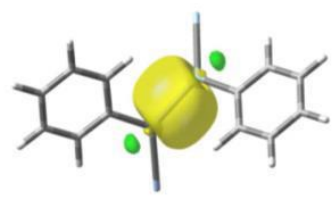

$\mathrm{Au}_{2}[\mathrm{Ph}-\mathrm{Si}-\mathrm{Si}-\mathrm{Ph}]^{2+}$

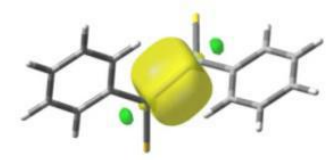

(a)
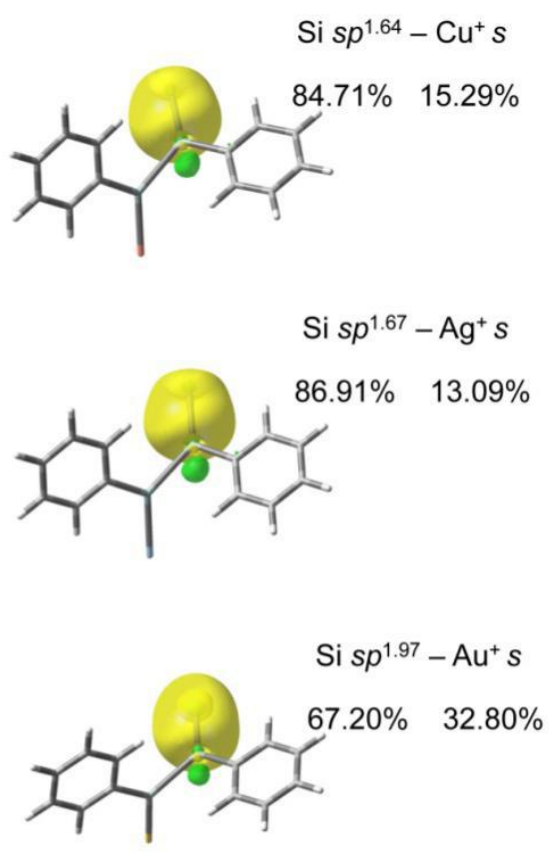

(b)

Figure S6. The natural bond orbitals of $\mathrm{M}_{2}^{\prime}[\mathrm{Ph}-\mathrm{Si}-\mathrm{Si}-\mathrm{Ph}]^{2+}\left(\mathrm{M}^{\prime}=\mathrm{Cu}, \mathrm{Ag}, \mathrm{Au}\right)$ (a) Al-Al $\sigma$ bond (b) one of Al- M' bonds.

(1) McWeeny, R., The valence bond theory of molecular structure-I. Orbital theories and the valence-bond method. Proceedings of the Royal Society of London. Series A. Mathematical and Physical Sciences 1954, 223, 63-79.

(2) Cooper, D., Valence bond theory. Elsevier2002; Vol. 10.

(3) Gallup, G. A.; Gallup, G. A., Valence bond methods: theory and applications. Cambridge University Press2002.

(4) Shaik, S. S.; Hiberty, P. C., A chemist's guide to valence bond theory. John Wiley \& Sons 2007.

(5) Wu, W.; Su, P.; Shaik, S.; Hiberty, P. C., Classical Valence Bond Approach by Modern Methods. Chem. Rev. 2011, 111, 7557-7593.

(6) Coulson, C. A.; Longuet-Higgins, H. C., The electronic structure of conjugated systems I. General theory. Proceedings of the Royal Society of London. Series A. Mathematical and Physical Sciences 1947, 191, 39-60.

(7) Van Lenthe, J.; Balint-Kurti, G., The valence-bond self-consistent field method (VB-SCF): Theory and test calculations. J. Chem. Phys. 1983, 78, 5699-5713.

(8) Song, L.; Mo, Y.; Zhang, Q.; Wu, W., XMVB: a program for ab initio nonorthogonal valence 
bond computations. J. Comput. Chem. 2005, 26, 514-521.

(9) Chen, Z.; Ying, F.; Chen, X.; Song, J.; Su, P.; Song, L.; Mo, Y.; Zhang, Q.; Wu, W., XMVB 2.0: A new version of Xiamen valence bond program. Int. J. Quantum Chem. 2015, 115, 731-737. 